\title{
PAKAIAN PANGULU DI NAGARI GUNUANG KOTA PADANGPANJANG PROVINSI SUMATERA BARAT
}

\author{
Robi Anwar ${ }^{1 *}$, Andar Indra Sastra ${ }^{2 *}$, Edward Zebua ${ }^{3^{*}}$ \\ Minat Pengkajian Seni Kriya Program Pascasarjana \\ Institut Seni Indonesia Padangpanjang \\ Jl. Bahder Johan, Guguak Malintang, Padangpanjang, Kota Padangpanjang, 27126. \\ Sumatera Barat. Indonesia \\ Email:anwarrobi715@gmail.com
}

\begin{abstract}
Abstrak
Penelitian ini mendiskripsikan tentang bentuk pakaian pangulu. Fokus penelitian ini adalah pakaian pangulu di Nagari Gunuang Kota Padangpanjang provinsi Sumatera Barat. Pakaian pangulu merupakan pakaian kebesaran seorang pemuka adat suatu kaum yang menyandang gelar pangulu. Pakaian pangulu mencerminkan nilai kewibawaan seorang pemimpin yang terlihat secara visual. Metode dalam penelitian ini menggunakan pendekatan kualitatif dengan tipe deskriptif. Teknik pengumpulan data dilakukan dengan studi pustaka, observasi, dan dokumentasi. Penelitian ini membahas tentang bentuk dan makna pakaian pangulu. Hasil tentang pakaian pangulu berupa pakaian adat untuk seorang pemimpin adat di Nagari Gunuang Kota Padangpanjang. Pakaian itu terdiri dari destar/saluak, baju hitam longgar/baju gadang, kain sandang/salempang, celana/sarawa, sarung/sisampiang, ikat pinggang/cawek, keris/karih, tongkat/tungkek. Makna dari pakaian pangulu adalah wibawa seorang pemimpin kaum dalam mengayomi anak kemenakan dan mampu menjadi hakim pada masyarakat.
\end{abstract}

Kata Kunci: pakaian, pangulu, bentuk, makna.

\begin{abstract}
This study describes the form of pangulu clothing. The focus of this research is pangulu clothing in Nagari Gunuang, Padangpanjang, West Sumatra province. Pangulu clothing is an oversized clothing of an adat leader, a people bearing the title pangulu. Pangulu's clothes reflect the dignity of a leader visually. The method in this study uses a qualitative approach with descriptive type. The technique of data collection is done by literature study, observation, and documentation. This study discusses the shape and meaning of pangulu clothing. The results of the pangulu clothing in the form of traditional clothing for a traditional leader in Nagari Gunuang, Padangpanjang City. The clothes consist of a sash/saluak, loose black clothes/gadang clothes, clothing/salempang cloth, pants/sarawa, sarongs/sisampiang, belts / cawek, keris/karih, sticks/tungkek. The meaning of pangulu's clothing is the authority of a leader of the people in protecting the children of nephews and being able to be judges in the community..
\end{abstract}

Keywords: clothes, pangulu, shape, meaning.

\section{PENDAHULUAN}

Minangkabau merupakan salah satu suku Bangsa di Nusantara yang mendiami kawasan Provinsi Sumatera Barat. Wilayah Minangkabau terdiri dari daerah darek dan rantau. Daerah darek terbagi kepada tigo luhak (tiga daerah); luhak Tanah Datar, luhak Agam, dan luhak Limapuluh kota. Adapun daerah rantau merupakan daerah perluasan dari kerajaan Minangkabau yang meliputi Solok, Pariaman, Pesisir Selatan, dan Pasaman serta daerah lain yang termasuk ke dalam adat dan budaya Minangkabau. Luhak Tanah Datar merupakan wilayah tertua di Minangkabau. Luhak Tanah Datar terbagi atas beberapa daerah seperti Sungayang, Padang Magek, Lintau Buo,
Batipuah X Koto, dan Padangpanjang yang merupakan bagian dari wilayah Luhak Tanah Datar (Idrus, 1994: 22-25).

Nagari Gunuang terletak di Kota Padangpanjang yang merupakan salah satu daerah penyebaran suku di Minangkabau yang berada dalam wilayah Luhak Tanah Datar. Sistem kekerabatan di Nagari Gunuang mengikuti sistem kekerabatan matrilineal. Dalam kekeabatan matrilineal garis keturunan berdasarkan garis keturunan ibu, sedangkan sistem pemerintahan adatnya dipimpin oleh seorang pangulu. Sebagai seorang pemimpin, tentunya pangulu memiliki sifat dan tingkah laku yang mencerminkan wibawa seorang 


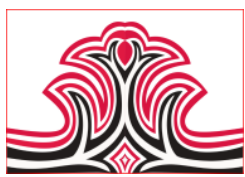

pemimpin, terutama dalam hal berbicara, bertindak, serta berpakaian.

Seorang pangulu dibedakan dari pakaian yang digunakannya, dan dihubungkan dengan prilaku yang menjadi kepribadian seoang pemimpin. Pakaian pangulu mengandung nilai kebesaran yang memiliki keterkaian dengan kepribadian pangulu, martabat pangulu, tugas pangulu, dan kepemimpinan pangulu dalam lingkungan sosialnya. Kebesaran seorang pangulu sebagai pemimpin kaum yang bewibawa terkandung pada pakaian yang digunakannya.

\section{KAJIAN TEORI}

Bentuk merupakan satu kesatuan dari berbagai unsur pendukungnya. Bentuk dapat diartikan sebagai kongkritisasi dari subject matter terhadap objek yang sedang diamati. Sedangkan makna merupakan nilai yang terkandung pada bentuk berdasarkan kaidah penggunaannya (Dharsono, 2017: 27-29). Begitu juga dengan bentuk dari pakaian pangulu, bentuk visual pakaian pangulu terdiri dari beberapa elemen pendukung yang menjadi bagian dari pakaian pangulu yang memiliki makna.

\section{METODE PENELITIAN}

Metode yang digunakan dalampenelitian ini adalah metode penelitian kualitatif dengan tipe deskriptif. Teknik pengumpulan data dilakukan dengan studi pustaka, observasi, dan dokumentasi. Tujuan dari penelitian deskriptif adalah untuk membuat deskripsi, gambaran secara sistematis, faktual, dan akurat mengenai fakta-fakta, sifat-sifat, serta hubungan antar fenomena yang diselidiki. Dengan menggunakan penelitian deskriptif, informasi dan data yang diperoleh di lapangan yang berkaitan dengan pakaian pangulu di Nagari Gunuang dipaparkan secara deskriptif. Data yang berkaitan dengan objek penelitian akan dikumpulkan sebaik mungkin guna mendapatkan hasil yang maksimal.

\section{HASIL DAN PEMBAHASAN}

\section{Hasil}

\section{1). Destar/ Saluak}

Destar/saluak merupakan penutup kepala yang digunakan oleh pangulu. Saluak merupakan kain batik yang ditata sedemikian rupa untuk menutup kepala bagi seorang pangulu. Saluak, pada bagian depan ditata berkerut-kerut yang berbentuk jenjang dan bagian atasnya datar, sedangkan bagian belakang berbentuk bundar dan melingkar di bagian belakang.
Gorga Jurnal Seni Rupa

Volume 08 Nomor 02 Juli-Desember 2019 p-ISSN: 2301-5942 | e-ISSN: 2580-2380

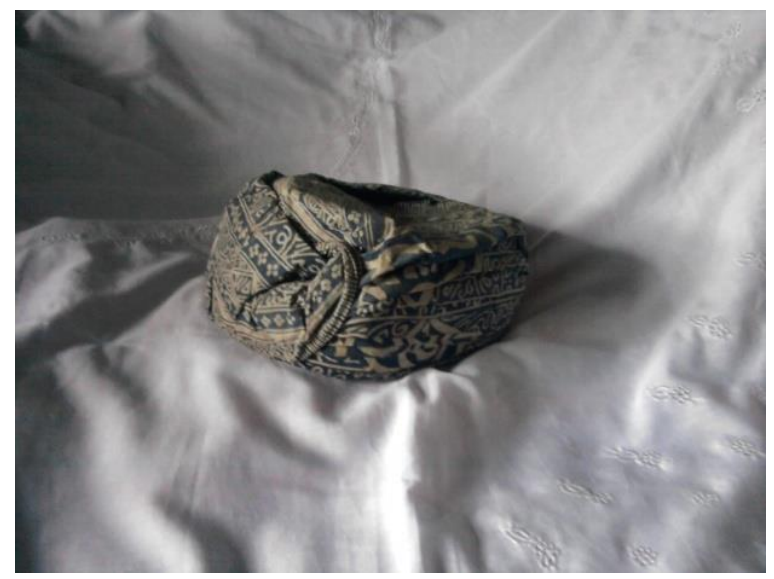

Gambar 1. Destar/ Saluak atau Penutup Kepala Pangulu Nagari Gunuang

(Sumber: Robi Anwar, 2014)

\section{2). Baju Hitam Longgar}

Baju hitam dan longgar adalah baju yang digunakan seorang pangulu pada upacara adat seperti batagak pangulu dan lain sebagainya. Baju ini berwarna hitam dan longgar, berbahan beludru dan dihiasi dengan benang emas pada bagian pinggirnya sebagai penghias, tidak memiliki saku, tidak memiliki krah, tidak memiliki kancing, dan pada bagian leher dibelah sampai dada tanpa kancing.

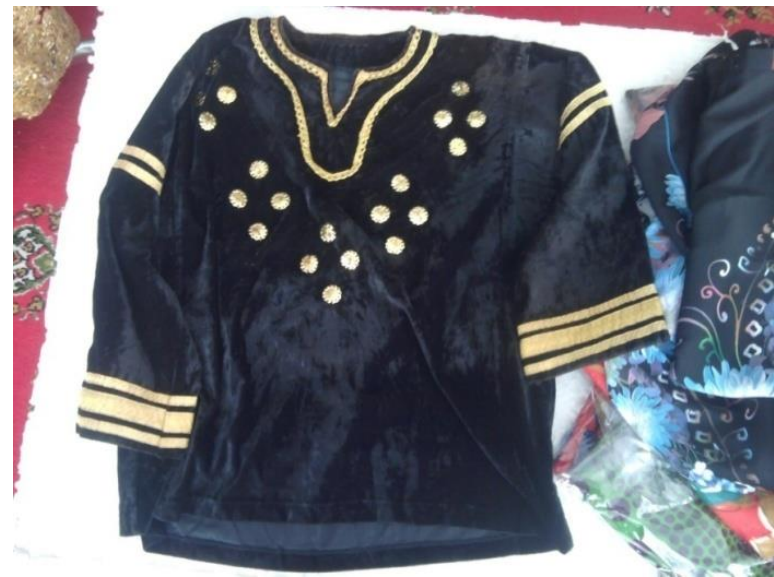

Gambar 2. Baju Pangulu Nagari Gunuang (Sumber: Robi Anwar, 2014)

\section{3). Kain Sandang/ Salempang}

Kain sandang/ salempang, merupakan yang kain disandangkan kebahu kiri. Kain ini adalah kain batik yang pada penggunaannya dilipat memanjang. 

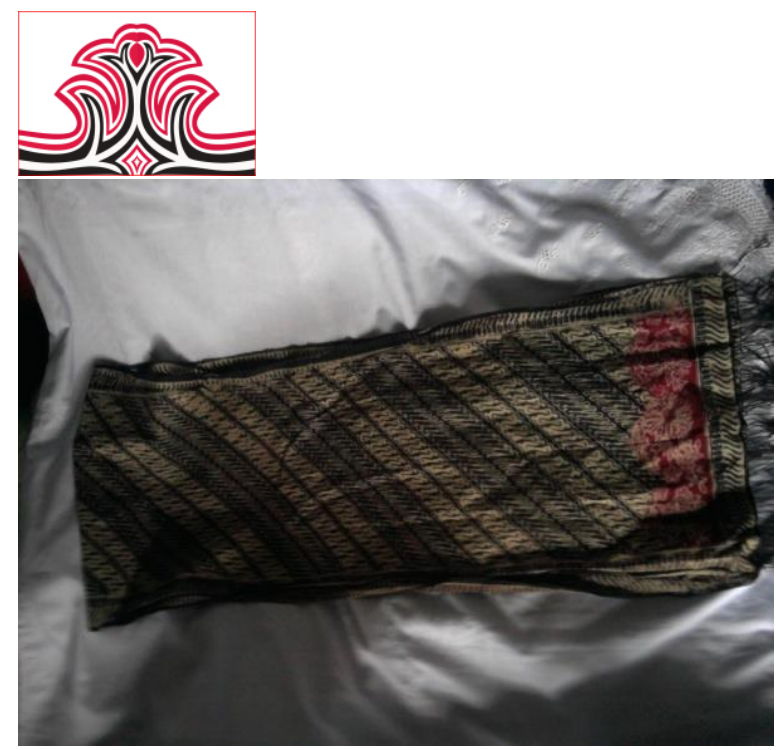

Gambar 3. Salempang Pangulu Nagari Gunuang (Sumber: Robi Anwar, 2014)

\section{4). Celana/ Sarawa}

Celana adalah penutup anggota tubuh pangulu mulai dari pinggang hingga pergelangan kaki, celana ini berwarna hitam dan longgar, terbuat dari kain berbahan beludru dan pada bagian bawah dihiasi dengan benang hias guna menambah nilai keindahan saat dipandang.

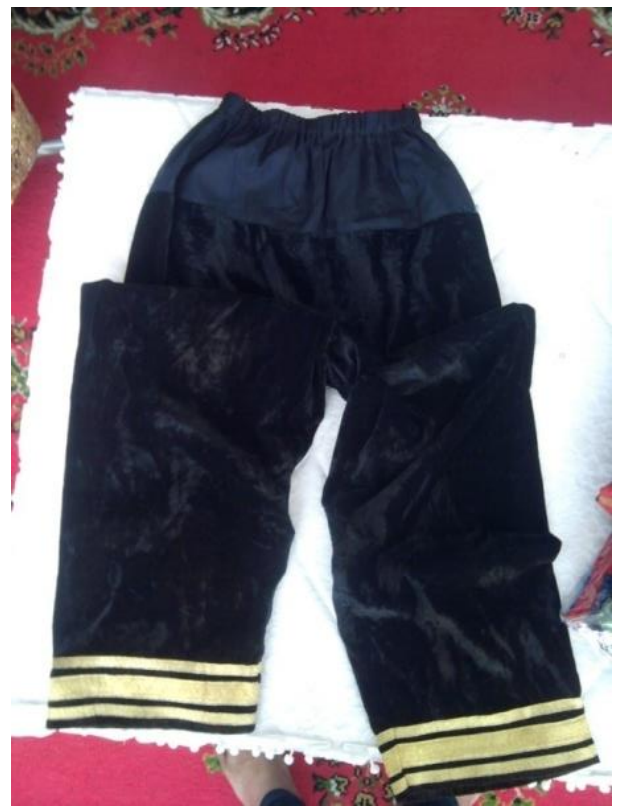

Gambar 4. Celana atau Sarawa Pangulu Nagari Gunuang (Sumber: Robi Anwar, 2014)

\section{5). Sarung/ Sisampiang}

Sisampiang adalah kain yang dipasang melingkar mulai dari pinggang sampai di atas lutut. Sisampiang ini biasanya berwarna merah dan pada seluruh permukaan kain biasanya disulam dengan benang emas.
Gorga Jurnal Seni Rupa

Volume 08 Nomor 02 Juli-Desember 2019 p-ISSN: 2301-5942 | e-ISSN: 2580-2380

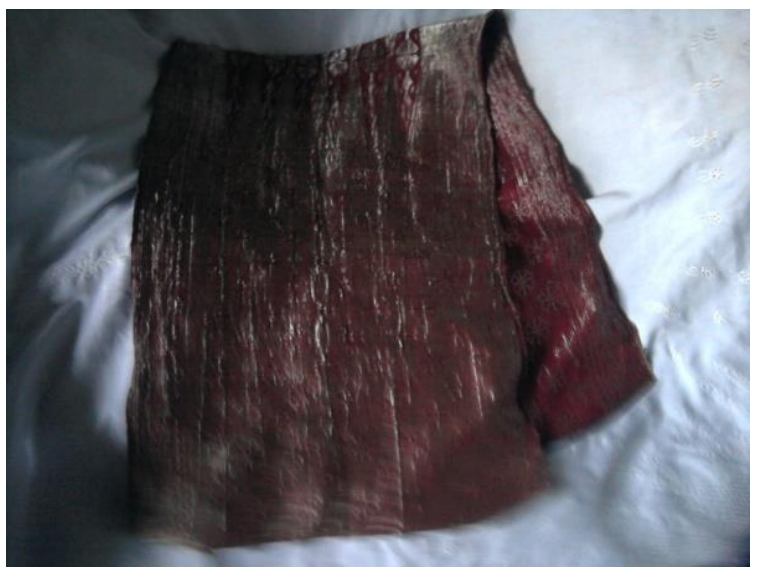

Gambar 5

Sisampiang Pangulu Nagari Gunuang

(Sumber: Robi Anwar, 2014)

\section{6). Ikat Pinggang/ Cawek}

Ikat pinggang Cawek adalah bagian paling luar yang terpasang setelah celana dan sisampiang. Cawek ini terbuat kain yang disulam dengan benang emas, kain ini biasanya berwarna merah dan pada bagian ujung memiliki jumbai.

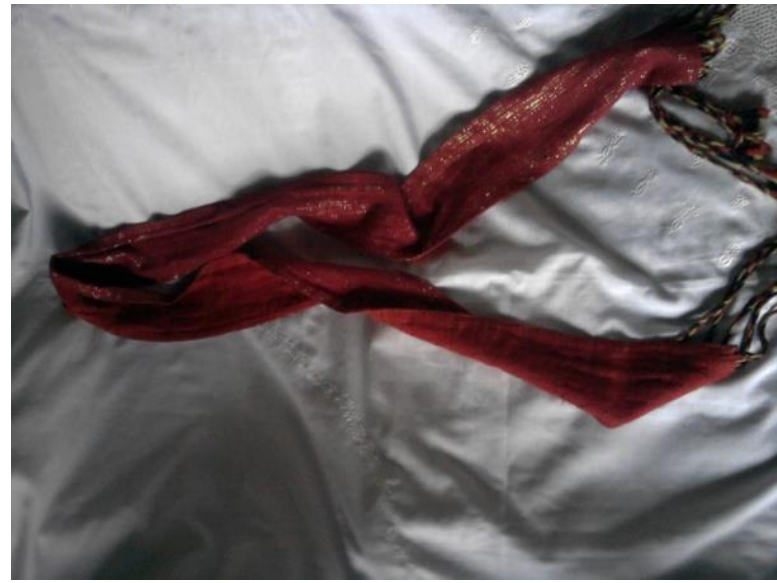

Gambar 6. Cawek atau Ikat Pinggang Pangulu-Pangulu Nagari Gunuang

(Sumber: Robi Anwar, 2014)

\section{7). Keris/ Karih}

Keris atau karih adalah sebuah senjata yang maksudkan untuk menjaga diri dari bahaya. Keris yang menjadi bagian penting pada pakaian pangulu diselipkan di perut sebelah kiri, keris ini tidak ditaroh di bagian belakang pinggang melainkan di bagian depan. 


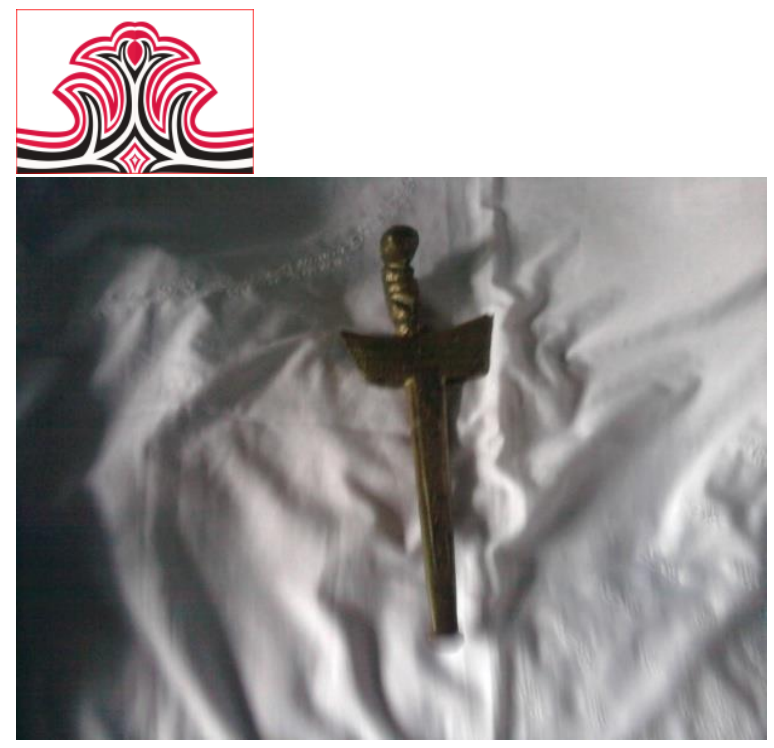

Gambar 7. Keris/ Karih Pangulu Nagari Gunuang (Sumber: Robi Anwar, 2014)

\section{8). Tongkat/ Tungkek}

Tongkat/tungkek bagi pangulu bukanlah alat bantu untuk berdiri atau berjalan, tongkat merupakan kelengkapan yang menjadi bagian penting bagi seorang pangulu. Bentuk dan ukuran tongkat tidaklah memiliki ukuran pasti, tergantung selera pangulu mengenai ukuran dan bentuk tongkat yang ia inginkan. Panjang tongkat berkisar antara 60-70 cm, dan pada bagian kepala ada yang polos dan ada yang dihiasi dengan hiasan perak, hiasan emas, dan ukiran.

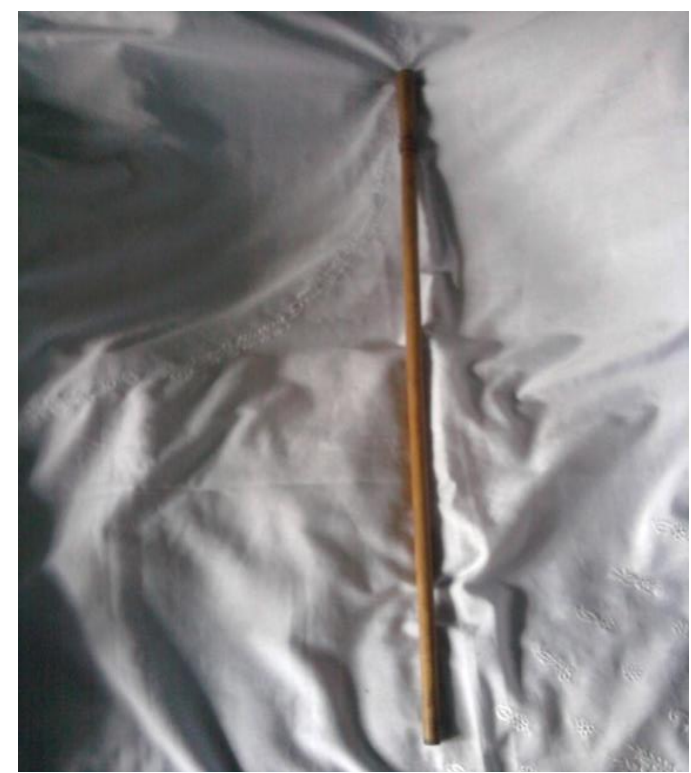

Gambar 8. Tungkek atau Tongkat Pangulu Nagari Gunuang (Sumber: Robi Anwar, 2014)

\section{Pembahasan}

\section{1). Destar/ Saluak}

Selain penutup kepela, saluak memiliki makna aturan hidup dan menggambarkan pemikiran seorang pangulu. Pangulu adalah orang yang memiliki banyak akal dan susah untuk ditafsirkan, hal ini dapat dilihat dari kerutan-kerutan yang tertata (Anwar Ibrahim,
Gorga Jurnal Seni Rupa

Volume 08 Nomor 02 Juli-Desember 2019 p-ISSN: 2301-5942 | e-ISSN: 2580-2380

1986: 28). Kerutan pada saluak terdiri dari lima kerutan, kelima lipatan ini memiliki makna bahwasanya pemerintahan adat memiliki lima unsur yang selalu serdampingan, yaitu; Pangulu, alim ulama, pemerintah, cerdik pandai, dan mantildubalang.

\section{2). Baju Hitam Longgar/ Baju Gadang}

Baju hitam dan longgar, bukan berarti baju yang digunakan oleh seorang pangulu itu terlalu besar dengan ukuran tubuhnya. Ukurannya yang besar merupakan bentuk yang dirancang sesuai dengan isi yang terkandung didalamnya, yaitu keterbukaan seorang pangulu dan kelapangan hati seorang pemimpin dalam menerima umpat-puji dalam menyelesaikan setiap permasalahan yang sedang dihadapi serta selalu ringan tangan dalam membantu. Tidak memiliki saku dan tidak memiliki kancing baju, melambangkan bahwa seorang pangulu tidak mencari keuntungan pribadi, tidak pandai menggunting dalam lipatan, berjiwa sabar, beralam lebar, berpandangan luas (Anwar, 1986: 29).

\section{3). Celana/ Sarawa}

Celana hitam memiliki makna langkah yang sigap untuk menjaga segala kemungkinan hadangan yang datang tiba-tiba. Walaupun lapang, tetapi langkah itu ada batasannya yang disebut dengan ukua jo jangko, ukua panjang tak buliah singkek, ukue singkek tak dapek panjang (ukur dengan jangka, ukur panjang tak boleh singkat, ukur singkat tak dapat panjang). Kedua kaki yang berjalan teratur diartikan sebagai sifat benar dan ikhlas, berjalan sendiri jangan hendak ditengah, berjalan berdua jangan hendak ditengah pula. Maksudnya adalah, jangan sombong seakan-akan kita yang lebih pandai dari orang lain, jangan berlindung kepada orang lain demi menyelamatkan diri kita (Anwar, 1986: 30).

\section{4). Kain Sandang/ Salendang}

Salendang adalah kain yang disandangkan di bahu seorang pangulu, kain ini memiliki makna sebagai kesiapan seorang pangulu dalam membimbing anak kemenakan. Kain sandang merupakan memiliki makna bahwasanya seorang pemimpin siap dalam memikul beban yang diamanatkan kepadanya. Salendang juga memiliki makna bahwa seorang pangulu harus mampu menghapus malu yang telah diperbuat oleh kaumnya (Anwar, 1986: 30).

\section{5). Sarung/ Sisampiang}

Sisampiang atau dikenal juga dengan sarung sebidang, karena kain ini hanya terpasang dari pinggang sampai di atas lutut. Kain ini memiliki makna kewaspadaan 
seorang pangulu dalam bertindak, semua pekerjaan haruslah ada ukurannya. Jadi, makna sisampiang adalah batasan tingkah laku seorang pangulu (Anwar, 1986: 30).

\section{6). Ikat Pinggang/ Cawek}

Makna dari ikat pinggang/Cawek adalah peranan seorang pangulu dalam melindungi anak, kemenakan, kaum, dan masyarakatnya. Peranan seorang pangulu menyatukan anak kemenakan serta masyarakat yang ada di nagarinya. Jika ada permasalahan kaum dan Nagari, maka pangulu memiliki tanggung jawab menyelesaiakan dan menyatukan kembali pihak yang bertikai (Anwar, 1986: 31).

\section{7). Keris/ Karih}

Keris adalah senjata yang digunakan untuk menikam, namun tidak digunakan sebagai alat untuk menikam oleh seorang pangulu. Letaknya condong kekiri bukan kekanan. Posisi keris yang miring kekiri bukan tanpa alasan, jika diposisikan dikanan maka keris akan mudah dicabut dan ditikamkan, karena keris pangulu hakikatnya bukan sebagai alat tikam. Dengan alasan itulah keris pangulu diposisikan dikiri, jika seorang pangulu dalam keadaan sulit untuk mengontrol emosi dan berniat menikamkan kerisnya, maka ia harus memindahkan terlebih dahulu posisi keris yang hendak dia gunakan kesebelah kanan, dengan harapan, sembari memutar keris keposisi kanan emosi seorang pangulu akan reda dan mengurungkan niatnya untuk menikamkan kerisnya. Dengan kata lain, keris memiliki makna bahwa seorang pangulu sanggup menguasai dirinya dan menjadi hakim bagi anak, kemenakan, serta kaum yang ada di Nagari (Anwar, 1986: 31).

\section{8). Tongkat/ Tungkek}

Tongkat/tungkek bagi pangulu bukanlah semata-mata sebagai alat bantu berdiri dan berjalan, namun memiliki makna tersendiri yang terkandung di dalamnya. Makna dari tongkat pangulu adalah bahwa seorang pangulu mampu menopang diri sendiri dan dapat dijadikan sebagai panutan bagi anak kemenakannya (Anwar, 1986: 31).

\section{KESIMPULA DAN SARAN}

\section{Kesimpulan}

Pakaian pangulu tidak hanya sebagai penutup anggota tubuh, akan tetapi juga sebagai identitas seorang pangulu di dalam suatu kaum atau di daerah dimana pangulu tersebut menetap. Pakaian pangulu merupakan penanda seorang pemimpin kaum dalam hidup bermasyarakat. Dalam kehidupan sehari-hari, pangulu tidak menggunakan pakaian kebesarannya
Gorga Jurnal Seni Rupa

Volume 08 Nomor 02 Juli-Desember 2019 p-ISSN: 2301-5942 | e-ISSN: 2580-2380

untuk menandakan bahwa dia seorang pangulu, akan tetapi cukup dengan berpakaian sopan serta menggunakan peci dan membawa kain sarung yang diletakkan dipundak.

Secara visual, pakaian pangulu dominan warna hitam dan taburan warna emas. Warna hitam merupakan warna dasar dari pakaian pangulu, warna hitam merupakan warna kepemimpinan dan dasar demokrasi adat Minangkabau, dan warna emas merupakan lambang kekayaan alam Minangkabau. Makna yang terkandung pada pakaian pangulu adalah nilai kepemimpinan dan wibawa seorang pemimpin dalam memimpin keluarga, kaum, dan Nagari.

\section{Saran}

Bekaitan dengan penelitian ini, diharapkan bagi seorang pangulu agar memahami nilai kepemimpinan seorang pemimpin kaum. Untuk masyarakat Nagari Gunuang, agar dapat menjaga kelestarian pakaian pangulu pada tiap kaum. Dan semoga dapat memberikan sumbangan terhadap ilmu pengetahuan, dan menjadi rujukan untuk peneliti berikutnya.

\section{DAFTAR RUJUKAN}

Anwar, Ibrahim. (1986). Pakaian Adat Tradisional Sumatera Barat. Padang: Departemen Pendidikan dan Kebudayaan.

Dharsono, Sony Kartika. (2017). Seni Rupa Modern. Bandung: Rekayasa Sains.

Idrus, Hakimy. (1994). Rangkaian Mustika Adat Basandi Syarak di Minangkabau. Bandung: PT. Remaja Rosdakarya. 